\title{
COMPARISONS OF TIME SERIES OF ANNUAL MEAN SURFACE AIR TEMPERATURE FOR CHINA SINCE THE I900S Observations, Model Simulations, and Extended Reanalysis
}

\author{
Qingxiang Li, Lei Zhang, Wenhui Xu, Tianjun Zhou, Jinfeng Wang, \\ Panmao Zhal, and Phil Jones
}

This paper assesses the similarities and differences of several annual average surface air temperature time series for China based on historical meteorological observations since the 1900s.

0 ver the past century, global-scale climate warming has been accelerating, and climate change is drawing increasing attention from the media and the public. Surface air temperature (SAT) is the major subject of concern within the context of climate change. Starting in the second half of the last century (after 1950), the warming of the climate has been obvious at the global scale (Brohan et al. 2006; Hansen et al. 2010; Lawrimore et al. 2011; Jones et al. 2012; Morice et al. 2012; Vose et al. 2012; Hartmann et al. 2013). In the Intergovernmental Panel on Climate Change's (IPCC) Fifth Assessment Report (AR5) headline statements from the Summary for Policymakers, it was noted that many changes in the climate system since 1950 are unprecedented when compared to earlier decades. From 1880 to 2012, the global average sea and land surface temperature shows an increasing linear trend of $0.85^{\circ} \mathrm{C}$. From 2003 to 2012 , the average temperature increased by $0.78^{\circ} \mathrm{C}\left(0.72^{\circ}-0.85^{\circ}\right)$ compared with that from
1850 to 1900 (Hartmann et al. 2013). Further, IPCC AR5 notes that the warming rate has slowed down recently (1998-2012). This short 15-yr period has been discussed by a number of authors (Easterbrook 2008; Easterling and Wehner 2009; Kaufmann et al. 2011; Fyfe et al. 2013; Guemas et al. 2013; Met Office 2013a,b,c; Karl et al. 2015; Lewandowsky et al. 2016).

Brohan et al. (2006) indicated that temperature series have three types of uncertainty: station errors, sampling errors, and bias errors. For China, the observational (station) errors in the SAT series are relatively small and well understood. Errors caused by the homogeneity adjustment of temperature series have been evaluated and discussed (Jones et al. 2008; Li et al. 2010a). Sampling errors in China are an issue when the number of observational sites is reduced

Publisher's Note: On 28 April 2017, this article was revised to correct the affiliation for Qingxiang Li and the legend in Fig. 6a. 
(Li et al. 2010a; Wang et al. 2014); this is especially relevant before the 1950s and in the 1940s. Bias errors, including the impacts of urbanization (Zhou et al. 2004) and/or land-use changes (Zhang et al. 2005) on SAT, are particularly important issues. Many efforts have been devoted to improved understanding of these sources of error in China, focusing on either individual regions, eastern China, or China as a whole. The results indicate that urbanization effects are weakest in western China and in the smaller cities. The urbanization effects are evident in some large cities, but the size of the effect across the whole country is relatively small (an order of magnitude smaller than the longer-term warming since 1900) (Jones et al. 1990; Li et al. 2004b, 2010b, 2014; Zhou et al. 2004; Zhang et al. 2005; Hua et al. 2008; Jones et al. 2008; Ren et al. 2008; Yan et al. 2009; Ren and Ren 2011; Yang et al. 2011; Wang et al. 2015).

The development of SAT time series averaged over mainland China has been a focus in the climate change research community throughout China (Zhang and Li 1982; Tu 1984; Ding and Dai 1994; Wang et al. 1998; Wang and Gong 2000; Chen et al. 2004, Zhai et al. 2004; Qin et al. 2005; Ding and Ren 2008; Wang et al. 2014). Currently, four sets of longterm time series exist that have been widely used in climate change studies in China: WangS, Tang, Li, and WangJ times series (see Table 1 for details). In this

AFFILIATIONS: LI-School of Atmospheric Sciences, Sun Yat-Sen University, Guangzhou, China, and National Meteorological Information Center, China Meteorological Administration, Beijing, China; ZHANG, AND XU-National Meteorological Information Center, China Meteorological Administration, Beijing, China; ZHOU-Key Laboratory of Atmospheric Sciences and Geophysical Fluid Dynamics, Institute of Atmospheric Physics, Chinese Academy of Sciences, Beijing, China; WANG-State Key Laboratory of Resources and Environmental Information System, Institute of Geographic Sciences and Natural Resources Research, Chinese Academy of Sciences, Beijing, China; ZHAl-China Academy of Meteorological Sciences, Beijing, China; JONES-Climatic Research Unit, School of Environmental Sciences, University of East Anglia, Norwich, United Kingdom, and Center of Excellence for Climate Change Research, Department of Meteorology, King Abdulaziz University, Jeddah, Saudi Arabia CORRESPONDING AUTHOR E-MAIL: Dr. Qingxiang Li, liqx@cma.gov.cn

The abstract for this article can be found in this issue, following the table of contents.

DOI:10.1175/BAMS-D-16-0092.I

A supplement to this article is available online (I0.1 I75/BAMS-D-16-0092.2)

In final form 22 August 2016

(02017 American Meteorological Society study, we supplement these four existing time series with two time series derived from the CRUTEM3 (Brohan et al. 2006) and CRUTEM4 datasets, which represent global historical land surface air temperatures and near-surface air temperature anomalies over land, respectively (Jones et al. 2012). Analysis of these six time series leads to divergent conclusions about SAT variations because of their differences in station densities and data-processing techniques.

Global climate models have shown reasonable performance on the global scale, but large uncertainties in regional-scale performance still exist. The performance of the models used in the third phase of the Coupled Model Intercomparison Project (CMIP3; Meehl et al. 2007) and CMIP5 (Taylor et al. 2012) for simulating Chinese SAT changes has been evaluated in many studies [for details on these simulations see the supplemental material for this paper (SM), which is available online at http://dx.doi.org//0.II75/BAMS -D-16-0092.2] (Zhou and Yu 2006; Xu and Xu 2012; Guo et al. 2013; Zhang et al. 2013; Jin and Zhou 2014). However, the observed time series used in these comparisons are different. The climate modeling community needs to pay more attention to the uncertainty of the observed time series. In addition, the first reanalysis product at centennial scales [Twentieth Century Reanalysis (20CR)], developed by the National Oceanic and Atmospheric Administration (NOAA), provides new opportunities for data-model comparisons. The near-surface air temperatures in 20CR provide useful results [especially in terms of the continuity of series; Cheng et al. (2013)] that can be verified by the simulation of global SAT variation (Compo et al. 2011, 2013). In this study, the SAT time series derived from $20 \mathrm{CR}$ data are also compared to the observational data.

The objective of this study is to assess the similarities and differences of these annual mean SAT time series for China based on historical meteorological observations since 1900 . The existing observed time series are compared to the results of CMIP5 model simulations and the 20CR reanalysis. The overall temperature trend of China SAT is investigated, and the characteristics of each type of data are discussed.

DATA AND METHODS. High-quality climate datasets are the basis for the detection and attribution of climate changes (Karl and Williams 1987; Gullet et al. 1990; Peterson et al. 1998). For years, temperature analyses across China, especially on local or subregional scales, saw discrepancies due to the inhomogeneity of the baseline data (Li et al. 2004a). To solve this problem, considerable efforts have been devoted to the homogenization of the SAT station 
data for China (Li et al. 2004, 2009; Song et al. 2004; Li and Yan 2009; Xu et al. 2013; SM). The first homogenized SAT datasets for the whole country, starting at the beginning of twentieth century, were published in 2010 (Li et al. 2010a). Currently, there are four sets of SAT time series that have been widely used in climate change studies in China (see Table 1 for details); these four sets of data are used in our analysis. The WangS series (Wang et al. 1998) and Tang series (Tang and Ren 2005) are described in Cao et al. (2013); the Li series (Li et al. 2010a) and WangJ series (Wang et al. 2014) are both developed from Li et al. (2010a).

In addition to the aforementioned China average time series, the CRUTEM3/4 datasets (Brohan et al. 2006; Jones et al. 2012) were also used to estimate the Northern Hemisphere/China surface temperature changes. Another homogenized global land surface air temperature (LSAT) dataset [Global Historical Climatology Network-Monthly (GHCN-M); Lawrimore et al. (2011)], developed by NOAA's National Centers for Environment Information (NCEI), was also used for comparison with the China observational dataset. The climate anomaly method (CAM; Jones and Hulme 1996) was applied to gridded deviations from the climatological average (anomalies) to construct a regional average time series over all of China.

The twentieth-century historical climate simulations of CMIP5 models (Taylor et al. 2012) were used in our analysis. The results of 41 CMIP5 models were compared to the historical observational data. Because the historical climate simulation of the CMIP5 models ends in 2005, our model-data comparison focuses on the period from 1900 to 2005. The Taylor diagram (Taylor 2001) was used in model evaluations. First, data from the 41 models were regridded to $1^{\circ} \times 1^{\circ}$ resolution grids, and the China average SAT series for each model was calculated by averaging all the anomalies series for each grid by latitude cosine weighting. This was nearly the same methodology applied by Jones and Hulme (1996) with the exception of a different resolution between the model $\left(1^{\circ} \times 1^{\circ}\right)$ and observation $\left(5^{\circ} \times 5^{\circ}\right)$ datasets. The China SAT series

\begin{tabular}{|c|c|c|c|c|c|}
\hline Series & Data coverage & $\begin{array}{l}\text { Quality } \\
\text { control }\end{array}$ & $\begin{array}{c}\text { Mean } \\
\text { temperature }\end{array}$ & $\begin{array}{l}\text { Calculation method } \\
\text { of regional series }\end{array}$ & Reference \\
\hline WangS & $\begin{array}{l}\text { Observations from } \\
\text { the China Meteo- } \\
\text { rological Adminis- } \\
\text { tration (CMA) and } \\
\text { proxy data }\end{array}$ & - & $\begin{array}{l}\text { Arithmetic average } \\
\text { of fixed observa- } \\
\text { tions (the times } \\
\text { were different) }\end{array}$ & $\begin{array}{l}\text { Subregional series derived by arith- } \\
\text { metic means of single series and na- } \\
\text { tional series through area-weighted } \\
\text { averaging across } 10 \text { regional series }\end{array}$ & $\begin{array}{l}\text { Wang et al. } \\
\text { (1998) }\end{array}$ \\
\hline Tang & $\begin{array}{l}\text { Observations from } \\
\text { CMA }\end{array}$ & - & $\begin{array}{l}\text { Arithmetic average } \\
\text { of } T_{\max }(T x) \text { and } \\
T_{\min }(T n)\end{array}$ & $\begin{array}{l}\text { Gridding then calculating the re- } \\
\text { gional series by the climate anomaly } \\
\text { method (CAM) }\end{array}$ & $\begin{array}{l}\text { Tang and } \\
\text { Ren }(2005)\end{array}$ \\
\hline $\mathrm{Li}$ & Same as above & $\begin{array}{l}\text { Homogenized } \\
\text { station series }\end{array}$ & Same as above & CAM & $\begin{array}{l}\text { Li et al. } \\
(2010 \mathrm{a}) \\
\end{array}$ \\
\hline WangJ & Same as above & $\begin{array}{l}\text { Same as } \\
\text { above }\end{array}$ & Same as above & $\begin{array}{l}\text { Biased Sentinel Hospitals Areal } \\
\text { Disease Estimation and Means of } \\
\text { Stratified Nonhomogeneous Surface } \\
\text { (BSHADE-MSN), which takes into } \\
\text { account prior knowledge of geo- } \\
\text { graphical spatial autocorrelation and } \\
\text { nonhomogeneity of target domains, } \\
\text { remedies the biased sample, and } \\
\text { maximizes an objective function for } \\
\text { the best linear unbiased estimation } \\
\text { of the regional mean quantity }\end{array}$ & $\begin{array}{l}\text { Wang et al. } \\
(2014)\end{array}$ \\
\hline CRUTEM3 & $\begin{array}{l}\text { Climatic Research } \\
\text { Unit (CRU) } \\
\text { temperature data } \\
\text { collected and } \\
\text { processed }\end{array}$ & $\begin{array}{l}\text { Same as } \\
\text { above }\end{array}$ & Same as above & CAM & $\begin{array}{l}\text { Brohan et al. } \\
(2006)\end{array}$ \\
\hline CRUTEM4 & $\begin{array}{l}\text { CRU temperature } \\
\text { data collected and } \\
\text { processed }\end{array}$ & $\begin{array}{l}\text { Same as } \\
\text { above }\end{array}$ & Same as above & CAM & $\begin{array}{l}\text { Jones et al. } \\
(2012)\end{array}$ \\
\hline
\end{tabular}




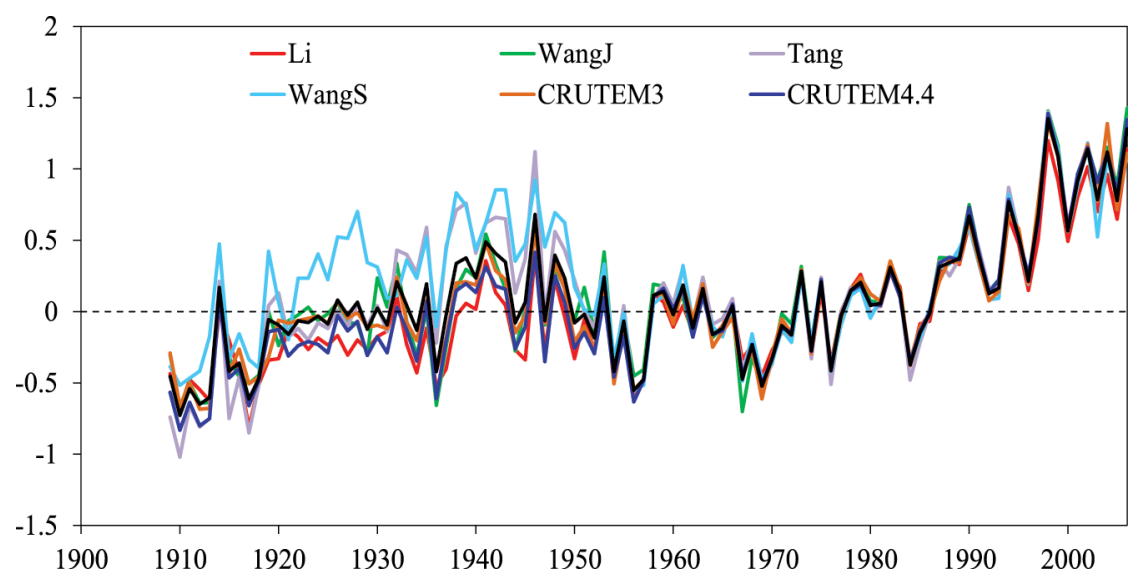

FIG. I. Six SAT time series across China during the past century (1909-2006, with 1961-90 as the base period).

was obtained by averaging all the selected model series (41 or 8 in this paper) using the same weighting.

Data from version 2 of $20 \mathrm{CR}$ were provided by the National Oceanic and Atmospheric Administration/ Office of Oceanic and Atmospheric Research/Earth System Research Laboratory/Physical Sciences Division (NOAA/OAR/ESRL/PSD), Boulder, Colorado (accessible from their website at www.esrl.noaa.gov /psd/). An average for China was calculated for the years 1900-2005 for additional comparisons with the CMIP5 simulations (for details of these simulations see the SM).

RESULTS. Comparison of observed time series. A comparison of the six time series of average SAT in China (see Table 1 for details; all series plotted relative to 1961-90 average) for the period of 1909-2006 (when all data are available) is shown in Fig. 1. Note that all series, with the exception of the WangS series, have a large amount of missing data from the western parts of China. For example, in the Li series (which has the densest observational station data coverage among the series with the exception of WangS) the length of gridpoint time series to the west of $110^{\circ} \mathrm{E}$ is 46-85 years. The station series for western China began between 1922 and 1961. The WangS series augmented western China station data with proxy climate data. First, they derived regional annual SAT series (starting in 1880) for northeast China, north China, east
China, south China, Taiwan, central China, southwest China, northwest China, Xinjiang, and Tibet based on observations. In addition, they included ice-core data from the Dasuopu Dunde and Guliya ice caps along the Tibetan Plateau, historical documentary information, and tree-ring data. Data for the WangS series were then obtained from Chinese SAT time series by area weighting the averages of all regions (Wang et al. 1998). The WangJ series differs from the others because a grid was not developed; instead, the Chinese average was calculated as one domain.

All six SAT series for China reveal similar decadal variations since the 1900s. The period from 1909 to 2006 can be divided into the following epochs: from 1909 to the mid-1940s (the first stage of the SAT rise), the mid-1940s to the late 1960s (the stage of SAT decline), and the late 1960s to 2006 (the second stage of accelerating SAT rise). The differences among the series are mainly evident during the period before the 1950s. The Tang anomaly series is slightly lower in the first 10 years, while the WangS anomaly series is higher than the other series from 1909 to 1929. From the 1930s to the 1950s, the WangS and Tang anomaly series are slightly higher than those of Li and WangJ. After the 1950s, the six series are in much closer alignment with each other.

The reason for the spread among the existing time series lies in the methods and the basic data used; homogenization of the basic climate data is

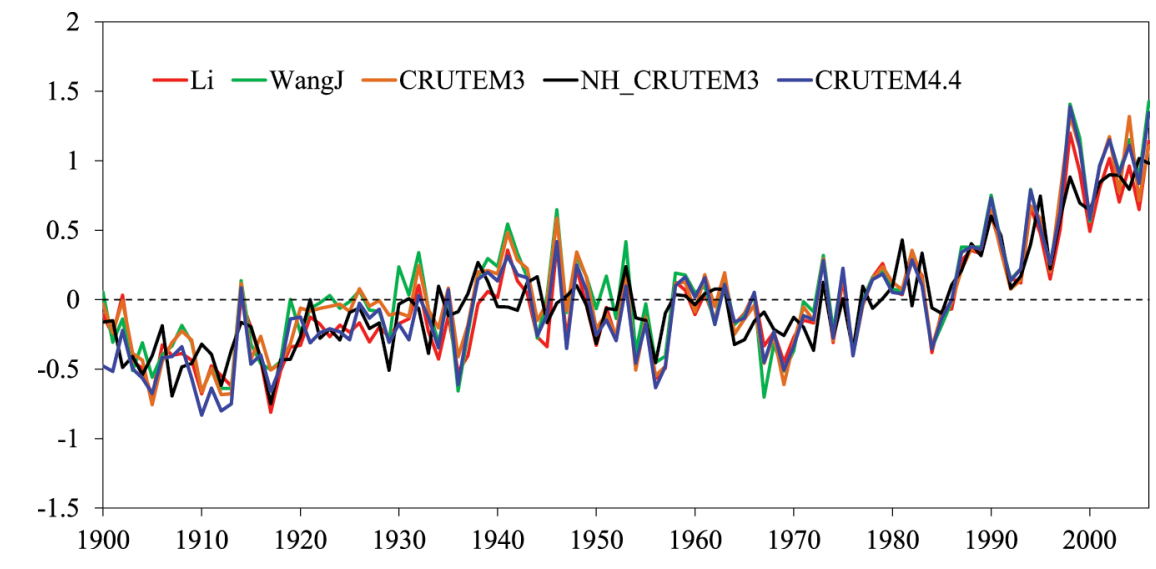

Fig. 2. Comparison of SAT series across China and the NH (NH_CRU, with 1961-90 as the base period). 
the key factor here. All of the homogenized series $(\mathrm{Li}$, WangJ, and CRUTEM3/4) show less variance among one other. CRUTEM3 always lies in the middle of the various series, $\mathrm{Li}$ and CRUTEM4 are consistently slightly below the other series between 1916 and 1951, and WangJ is slightly below all the other series around 1936 and 1968. The basic data used for establishing the Li and WangJ series are identical, but the two series differ slightly from each other as a result of the utilization of different statistical methods (even after the 1950s). Tang uses nonhomogenized station data but is closer to the other four series than WangS, which uses noninstrumental proxy data for the annual averages before the 1950s.

Four series are compared in Fig. 2 (CRUTEM3, CRUTEM4, WangJ, and Li). For additional comparison with larger-scale SAT variations, we also include the series for the Northern Hemisphere (NH_CRU), calculated using CRUTEM (here, we include both NH SAT series calculated from CRUTEM3 and CRUTEM4, which are extremely similar). The $\mathrm{NH}_{-}$ CRU series also has high consistency with the Chinese series, which is similar to the findings of Bradley et al. (1987). This is likely related to the fact that China is a large midlatitude country and is a significant part of the NH landmass [see discussions in Jones et al. $(1997,2012)]$. The China average series reveal a more pronounced warming period starting in the 1940s, with 1946 as the warmest year before 1980; however, for NH_CRU, the warmest year before 1980 is 1938. Thus, the first twentieth-century warming phase for NH_CRU ends earlier than in China's series, and the subsequent $\mathrm{NH}$ temperature decline also ends earlier, which is consistent with Bradley et al. (1987).

Comparative analysis of the China SAT time series simulated by climate models and reanalysis. The annual mean SAT series simulated by 41 models for 1900-2005 (using 1961-90 as the base period) is shown in Fig. 3. As evident from the ensemble mean of the models (blue curve), the simulated SAT anomalies from the early 1920 s to the 1960s are generally higher than those of
Mean Surface Air Temperature in China

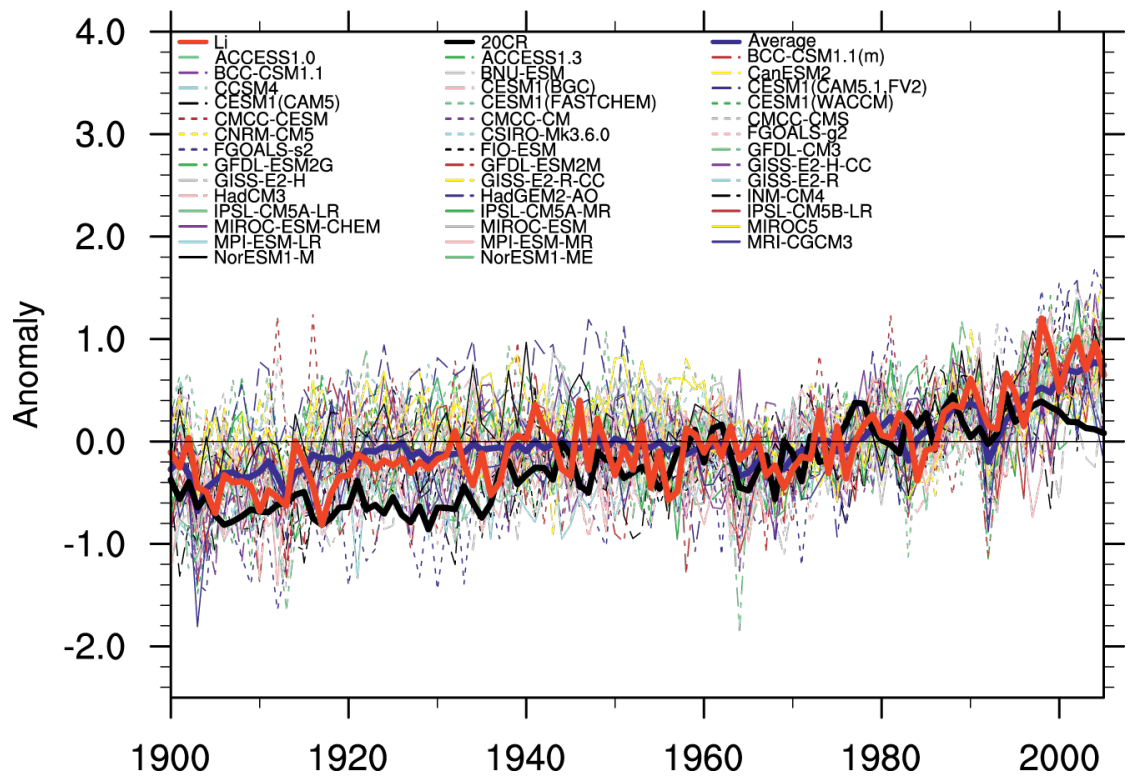

FIG. 3. China SAT series variations simulated by 41 models in CMIP5 in the past century (with 196I-90 as the base period). The red, black, and blue lines CR, and multimodel average, respectively.

the observed series (red curve), with an average differences close to $0.3^{\circ} \mathrm{C}$ before the 1940s. After the 1950s, the simulated rate of climate warming is still lower than the observations (Fig. 4b). A comparison between the long-term temperature change estimated by multiplemember ensemble historical runs from 41 models and seven observational series [the eastern China series by Cao et al. (2013) is also included here] is shown in Fig. 4a. The rate of change of mean SAT for China simulated by the 41 models for $1900-2005$ is approximately $0.00^{\circ}-0.20^{\circ} \mathrm{C}$ decade $^{-1}$, with an average of $0.06^{\circ} \mathrm{C}$ decade $^{-1}$, and the average rate simulated for 1951-2005 is $0.15^{\circ} \mathrm{C}$ decade $^{-1}$ [less than the $0.19^{\circ} \mathrm{C}$ decade $^{-1}$ for observation (Li)]. The seven observational series exhibit different trends centered at approximately $0.09^{\circ} \mathrm{C}$ decade $^{-1}$ (red line in Fig. 4a). The trends for the model series are slightly smaller than those for observational series at the centennial scale, but the agreement is better for the last 55 years (1951-2005; see Fig. 4b).

Two additional approaches are adopted to additionally evaluate the simulation of the SAT anomalies over China. First, Pearson correlation coefficients (CCs) between the observational and simulated series for the full 106 years (1900-2005) are calculated. The highest CC is 0.75 , found for the Flexible Global Ocean-Atmosphere-Land System Model, second spectral version (FGOALS-s2), which was developed by the Institute of Atmospheric Physics (IAP), Chinese Academy of Sciences (CAS). In decreasing order of CC (larger than 0.6), the remaining seven 
(a) 1900-2005

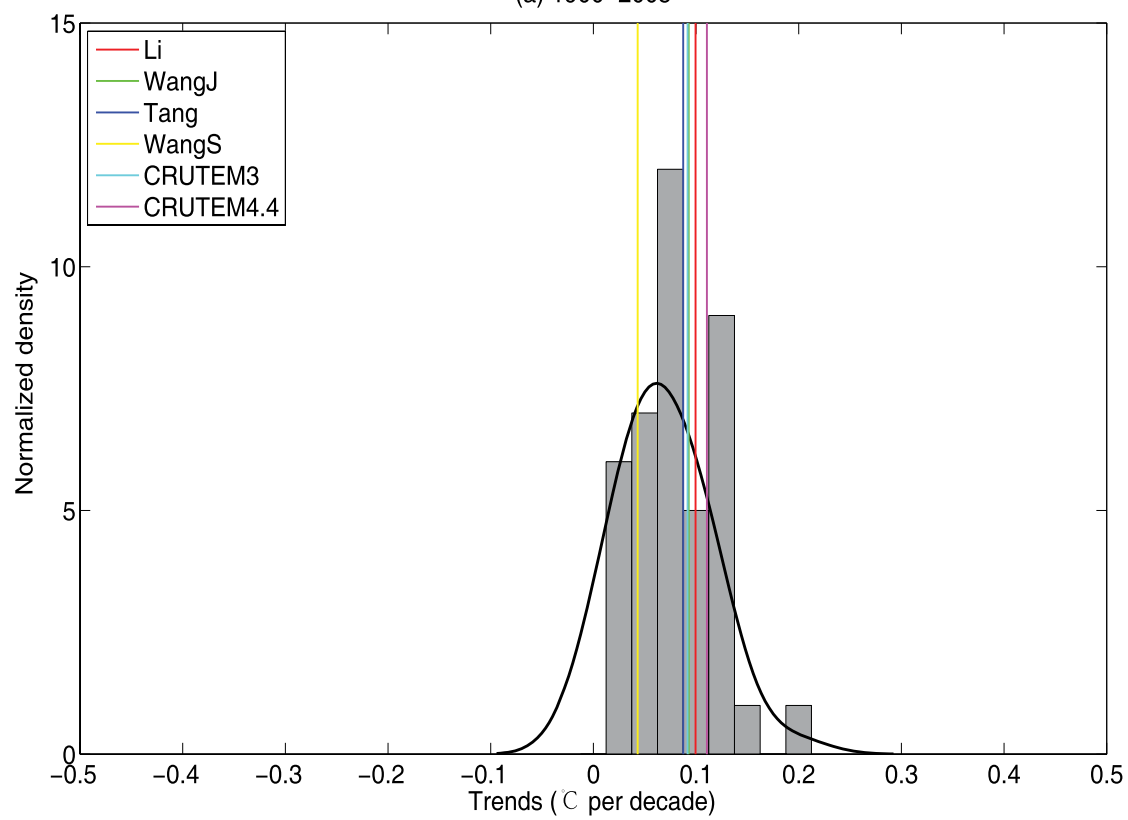

(b) 1951-2005

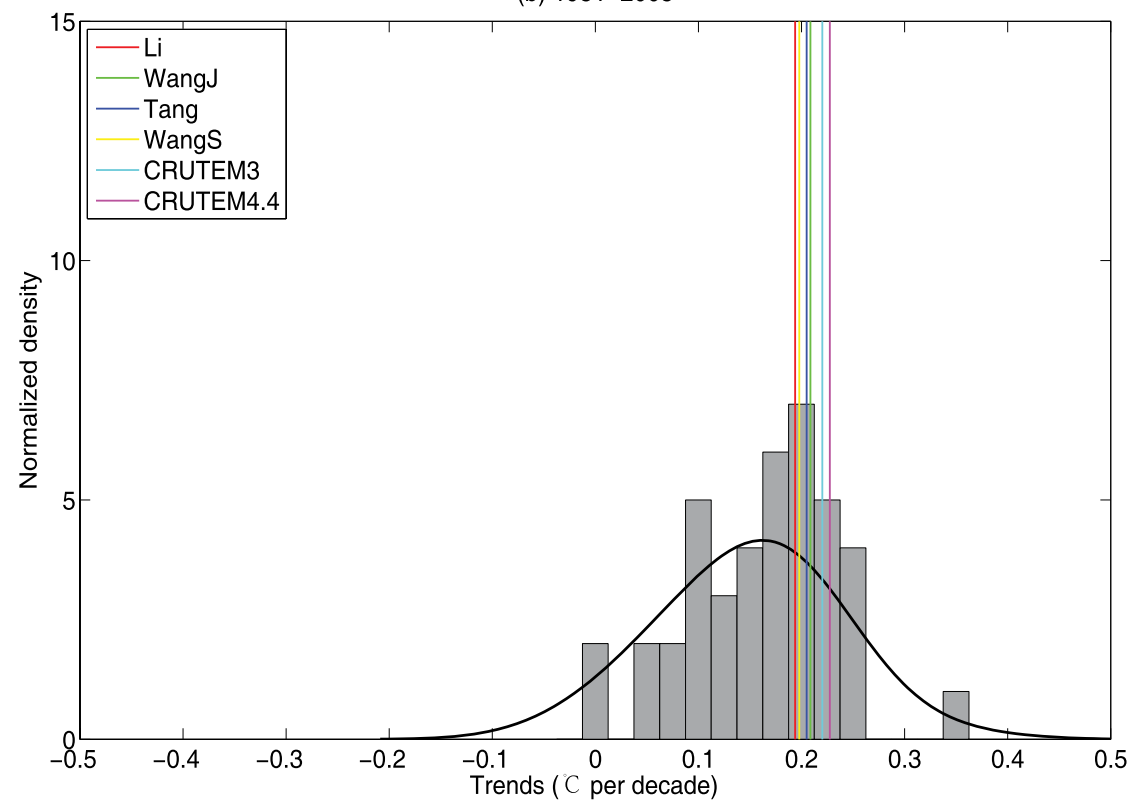

FIG. 4. Comparison of long-term temperature change trends for 41 models in CMIP5 and six observational series: (a) 1900-2005 and (b) 195I-2005. The bars indicate the trend distributions of 41 models (the black curve is a fitted line), the straight lines indicate the trends of six observational series, and the red line indicates the Li series trend.

top-ranking series are the Max Planck Institute Earth System Model, medium resolution (MPI-ESM-MR), with a value of 0.69 ; the Beijing Climate Center, Climate System Model, version 1.1 (BCC-CSM1.1), with a value of 0.67 ; the Beijing Normal UniversityEarth System Model (BNU-ESM), with a value of 0.67; the L'Institut Pierre-Simon Laplace Coupled Model, version 5A, low resolution (IPSL-CM5A-LR), with a value of 0.65 ; the BCC-CSM1.1, with a value of 0.62; the Community Earth System Model, version 1 (Whole Atmosphere Community Climate Model) [CESM1 (WACCM)], with a value of 0.62 ; and the CESM1 [Community Atmosphere Model with Chemistry (CAM-chem)] [CESM1 (FASTCHEM)], with a value of 0.61 . It is interesting to note that four out of the eight top-ranking simulated series for China are derived from models developed by Chinese institutes. Another important observation is that using the homogenized series from $\mathrm{Li}$ provides higher correlations (the CCs shown here are higher than those given by Zhang et al. (2013), where the unadjusted (raw) observation data were used).

Figure 5 (Taylor diagram) is akin to Jiang and Tian (2013), which shows the performance of the models in their historic simulations of SAT anomalies from 1900 to 2005 . The closer the distance between model series and REF (observations here are referring to the Li series), the better the performance of the corresponding model. The topranking models by distance are BCC-CSM1.1; the Geophysical Fluid Dynamics Laboratory Earth System Model with MOM, version 4 component (GFDL-ESM2M); the Centro EuroMediterraneo per I Cambiamenti Climatici Climate Model (CMCC-CM); the Second Generation Canadian Earth System Model (CanESM2); the CESM1 (Community Atmosphere Model, version 5) [CESM1 (CAM5)]; Norwegian Earth System Model, version 1 (intermediate resolution) (NorESM1-M); Model for Interdisciplinary Research on Climate, Earth System 
Model (MIROC-ESM); and MPI-ESM-MR. The average of the eight top-ranking models (whose normalized standard deviation is below 2.0) reproduces the SAT observational variations for the last 106 years with a correlation coefficient of 0.81 (Fig. 6a). Compared with the observations ( $\mathrm{Li}$ ), the model series average underestimates the observations before the 1970 s except for the short period in the 1950s. As observed in Fig. 6b, the average of the eight top-ranking models reproduces the SAT observational variations for the last 105 years with a correlation coefficient of 0.79 , which is slightly lower than in Fig. 6 a. However, as a whole, the average model series agrees well with observations during the entire period.

Figures 3 and 6 also display the regional SAT time series of China calculated from 20CR (black bold lines). During the entire twentieth century, the long-term SAT warming trend for China is very well reflected in $20 \mathrm{CR}$. For $20 \mathrm{CR}$, the early temperature rise continues from the 1900s to the 1960s, followed by a sudden decline at the beginning of the 1960s and then a rise again after the mid-1960s. The average rate of rise of China's SAT for 1900-2005 calculated by $20 \mathrm{CR}$ data is $0.10^{\circ} \mathrm{C}$ decade $^{-1}$, which is close to the level of the observed time series $\left(0.09^{\circ} \mathrm{C}\right.$ decade $\left.^{-1}\right)$. In $20 \mathrm{CR}$, temperatures begin to decrease in the mid-1990s. It is important to note that the analytical model of the 20CR dataset is driven by monthly average sea surface temperatures, and only surface pressure data are assimilated. Therefore, the SAT estimates obtained are completely independent from the myriad of land surface temperature observations. Without assimilating surface air temperature and/or time-varying anthropogenic aerosol data (though volcanic aerosols were included), the 20CR succeeded in reproducing the recent winter SAT cooling features in China but failed in reproducing the significant summer warming trends in southern
China from 1998 to 2012 (Li et al. 2015; Fig. ES3 in $\mathrm{SM})$. This has led to the underestimation of China's average SAT in the past 15 years.

DISCUSSION. SAT anomalies in the 1940s. OBSERVATIONS. There is little doubt about the high SAT anomaly during the 1940s over China because all six observational series collected for this study consistently show similar features (Fig. 1). However, the magnitudes of the SAT anomalies differ among these datasets ( $\mathrm{Li}$ et al. 2010a). In the WangS series, the 1910s to the 1950s are warmer than the other series, while the Tang series only shows the high-temperature anomalies in the 1940s. The two series achieve comparable amplitudes in 1946 (WangS and Tang are $0.68^{\circ}$ and $0.88^{\circ} \mathrm{C}$, respectively) with some years in the most recent warm period (2000s), while the remaining series have relatively lower amplitude $\left(0.31^{\circ} \mathrm{C}\right.$ for $\mathrm{Li}, 0.38^{\circ} \mathrm{C}$ for Wang $)$, and $0.36^{\circ} \mathrm{C}$ for CH_CRU in 1946). Note that the only difference between $\mathrm{Li}$ (and WangJ) and the Tang series is that the former two series used a homogenized dataset, while 

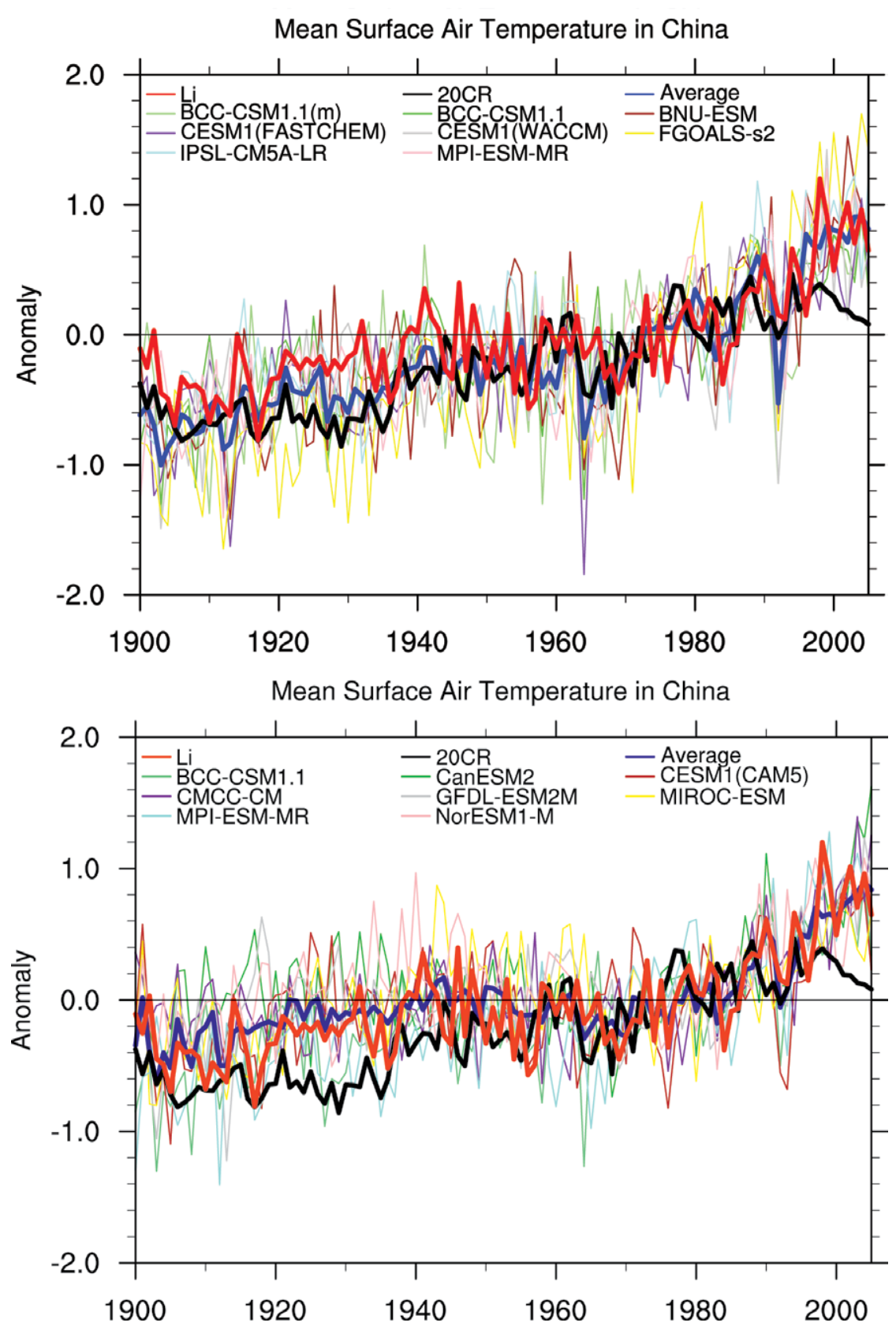

FIG. 6. Series of China SAT variations simulated by the eight top-ranking models in the CMIP5 and 20CR datasets (with 196I-90 as the base period). Ranking by (top) correlation coefficients only and (bottom) correlation coefficients and normalized standard deviation.

the latter did not, which indicates that data homogenization is likely to be the most significant cause of differences in the anomalies during the 1940s.

The uncertainties for SAT change series (Li) have been assessed in Li et al. (2010). Based on their evaluation, the average $95 \%$ annual uncertainty range is about $0.327^{\circ} \mathrm{C}$ during the $1940 \mathrm{~s}$ (1941-50), so the decadal uncertainty would be $0.327 / \sqrt{ } 10 \approx 0.1^{\circ} \mathrm{C}$, which is smaller than $0.15^{\circ} \mathrm{C}$ in the 1930 s, and about $0.20^{\circ}-0.22^{\circ} \mathrm{C}$ in the 1900s, 1910s, and 1920s (Fig. ES2 in SM). Most of the uncertainty comes from the limited data coverage (Li et al. 2010, see their Fig. 5), and it agrees well with the station number changes during the 1900s to 1940s for eastern and western China (E China and $\mathrm{W}$ China), respectively (Fig. ES1 in SM). Western China has similar interannual and decadal changes with E China from the 1930s to the 2010s. This assures that the Li series can present the SAT change for all of China to a certain extent even if the series was built based on only the stations from E China in the earlier years (1900s to 1920s).

Because the observational data in the 1940s were disrupted because of World War II from 1937 to 1945, certain difficulties are associated with the detection of SAT variation in this time period. The Li series basically reflects the average for all 30 of the stations' SAT anomaly changes since 1930s in western China (Fig. 7). Wang et al. (1998) introduced proxy data (tree rings, ice cores, and historical documents) to enhance estimates for the western half of China. But how to reliably estimate the missing instrumental observation with proxy data remains an open question. Annual averages for $\mathrm{NH}$ midlatitude continental areas are principally dominated by temperatures in winter, but proxy sources are mostly indicative of the summer half of the year. And the WangS series is composed of annual averages and does not include separate series for the seasons (Wang and Gong 2000). Even though the use of proxy data has the problems above, increasing the data coverage in the west is still a valuable endeavor and is worthy of further study with better proxy data and a more perfect treatment method. 
CMIP5 AND 20CR. Zhou and $\mathrm{Yu}$ (2006) noted that CMIP3 models do not yield a good simulation of abnormal climate warming in China in the 1940s, which may be related to the absence of solar forcing variations that should change over time between different simulation experiments for the twentieth century. For historical climate simulations using the CMIP5 models, most models still failed to reproduce the warmth of the 1940s. As is evident from the comparison between the average of the simulations using all models and the observed time series in Fig. 3, the warmth in the 1940s is less evident in the simulations. Using the observational average SAT time series (Li series) that has been established from the homogenized data used in Zhou and $\mathrm{Yu}$ (2006), the amplitude of the temperature rise before the 1940s is much lower and the extent of the abnormal temperature rise in the 1940s is also less significant. This result is also consistent with the 20CR data (Fig. 3). The 20CR reanalysis is somewhat like AMIP-type experiments, but the comparison of this aspect has been addressed in Compo et al. (2013). They showed that assimilations of the MSLP data were an improvement over the AMIP-type models (which featured only SST/sea ice assimilation). It seems that the abnormal climate warming revealed by the SAT time series in the 1940s may not be as high as the WangS and Tang series indicate.

Temperature change trend estimates from 1900 to 2015. In this section, we consider the series that includes the most recent year (2015), so only some of the series [CRUTEM4, GHCN-M (Lawrimore et al. 2011), and Li $+\mathrm{Xu}$ (Li et al. 2010); the data since 2007 are derived from Xu et al. 2013)] can be used. The temperature anomaly series at the annual time scale are shown in Fig. 8.
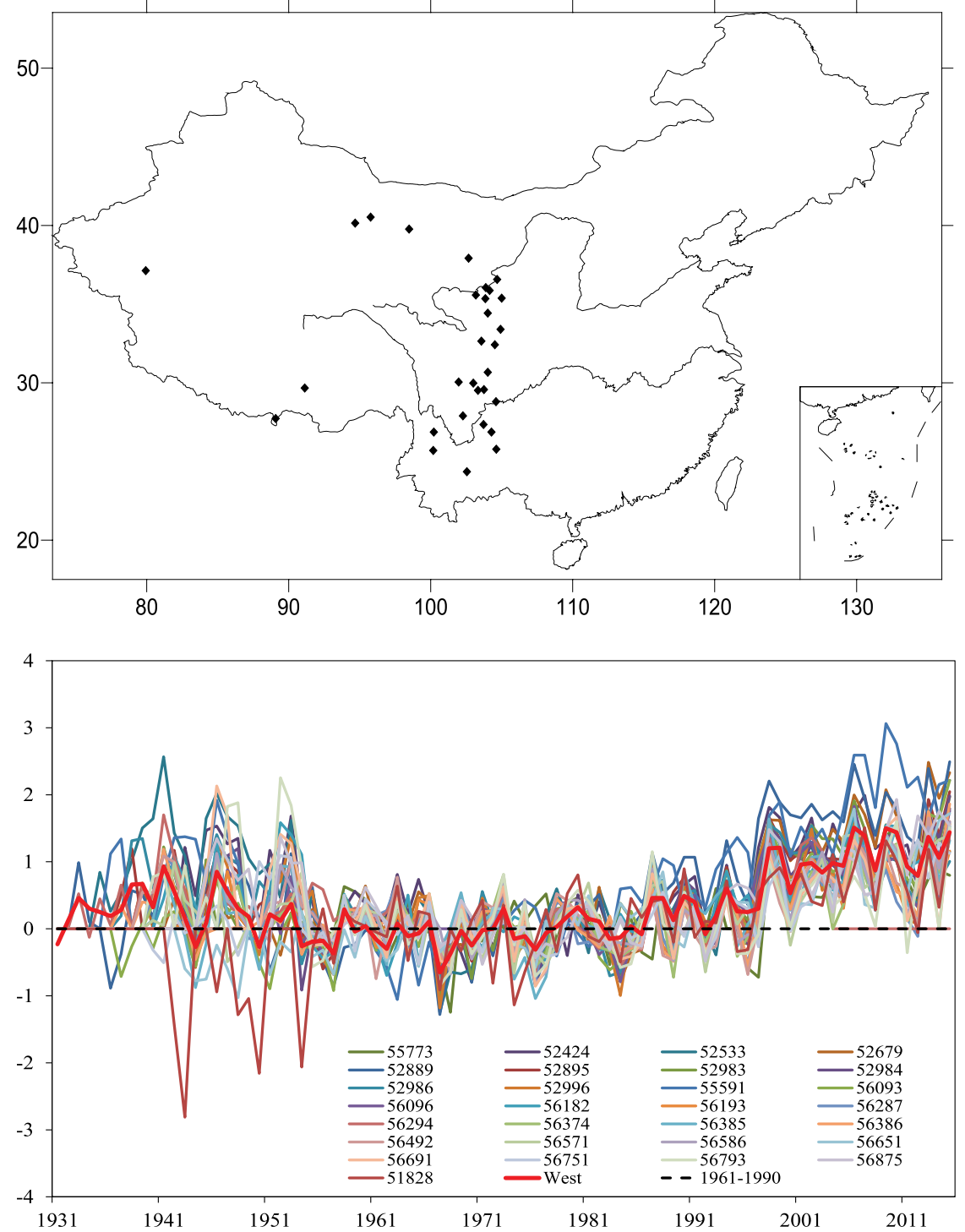

Fig. 7. The distribution of the long-term stations used to construct the (top) west China series and (bottom) W China series and the 30 station series (with 196I-90 as the base period).

The linear change trends and 95\% uncertainty ranges (Ebisuzaki 1997) are calculated in Table 2. Over the period from 1900 to 2015 , the annual linear trend coefficients are $0.121^{\circ}, 0.130^{\circ}$, and $0.114^{\circ} \pm 0.009^{\circ} \mathrm{C}$ decade $^{-1}$ for $\mathrm{Li}+\mathrm{Xu}, \mathrm{CRUTEM} 4$, and GHCN-M version 3 (v3), respectively. All are slightly larger than the raw ("unadjusted" in the "Comparative analysis of the China SAT time series simulated by climate models and reanalysis" section) data $\left(0.107^{\circ} \pm 0.009^{\circ} \mathrm{C}\right.$ decade $\left.^{-1}\right)$. The difference between the raw and adjusted data happens mainly before the 1950s.

Finally, we consider the most recent period (1998-2015) in more detail. During this period, Li et al. (2015) state that a hiatus in warming occurs in most parts of China except for the southwest [as 


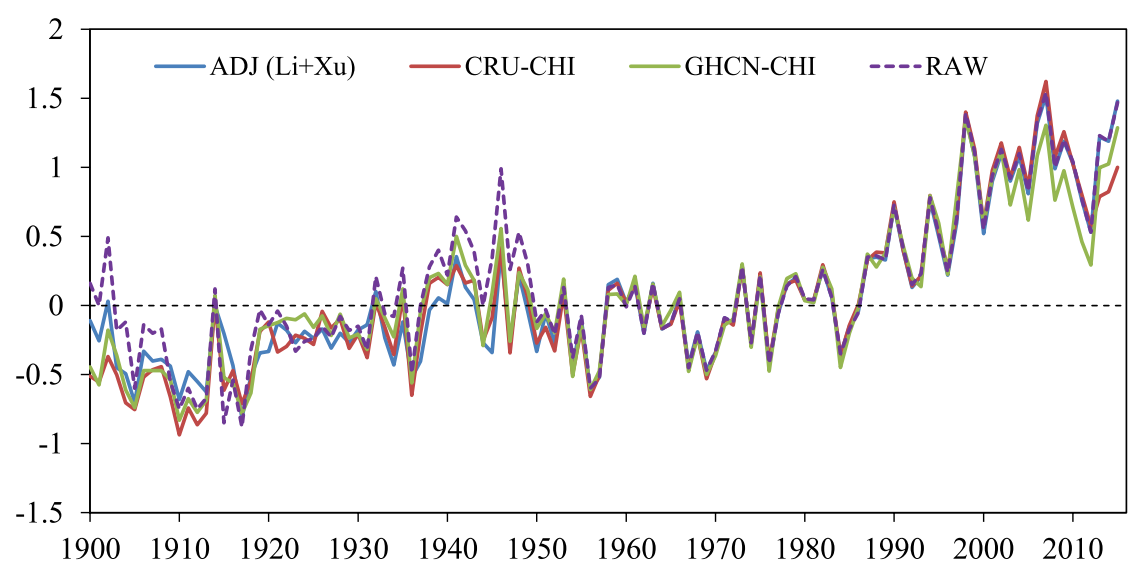

FIG. 8. Anomaly time series of China's average annual SAT from 1900-20I5 (1961-90 as the base period)

also noted by Duan and Xiao (2015)]. Although 2015 is the second-warmest year on record (2007 is the warmest year), the temperature change trend for 1998-2015 remains $0.079^{\circ} \pm 0.13^{\circ} \mathrm{C}$ decade $^{-1}$, which is still much smaller than estimates for 1951-2015 $\left(0.244^{\circ} \pm 0.021^{\circ} \mathrm{C}\right.$ decade $\left.^{-1}\right)$ and for $1979-2015\left(0.379^{\circ}\right.$ $\pm 0.044^{\circ} \mathrm{C}$ decade $^{-1}$ ) (Fig. 7). This agrees well with Li et al. (2015), though the recent trend is slightly larger than the 1998-2012 period trends. China averages calculated by both CRUTEM4 and GHCN-M v3 show negative trends during the 1998-2015 period, both of which are related to the slight underestimation of the temperature in recent years. It is worth noting that over this period none of the series have trends that are statistically significant at the $5 \%$ level.

CONCLUSIONS AND PROSPECTS. With the motivation of recommending the best estimates of Chinese average SAT series to the international climate research community, we have assessed the similarities and differences among the existing time series of annual average SAT for China. These time series are based upon historical meteorological observations since the 1900s, and the observed time series are further compared to the historical climate simulation of CMIP5 models and the twentieth-century reanalysis. Our major findings are summarized below.
1) Although there are still certain differences among the existing Chinese average time series during the 1940s warmth period that are due to the scant number of observations, SAT time series using homogenized temperature data have improved the agreement in longterm changes among all the datasets since the 1900s. The similarity between the Chinese observational average and the $\mathrm{NH}$ series, noted by Bradley et al. (1987), is confirmed, but the $\mathrm{NH}$ series peaks slightly earlier (1938) than does the China series (1946).

2) SAT time series using homogenized temperature data have also improved the agreement in long-term changes between the observational and model simulation datasets since the 1900s. Several Chinese models used in CMIP5 show better performance in the simulation of annual SAT variations over China in the past century in terms of correlation coefficients (all above 0.6). These models consistently show reasonable reproductions of decadal-scale variations of SAT in the past century, but tend to overestimate recent trends during the past 15 years. The 20CR simulations also reflect the interdecadal variations of China's SAT at the century scale but greatly underestimate the temperature during the past two decades.

3) A new evaluation of the long-term trend based on the homogenized observed data was achieved: SAT in China reveals a warming trend $\left(0.121^{\circ} \pm 0.009^{\circ} \mathrm{C}\right.$ decade $^{-1}$ ) slightly greater than what the raw data indicates $\left(0.107^{\circ} \pm 0.009^{\circ} \mathrm{C}\right.$ decade $\left.^{-1}\right)$ from 1900 to 2015. The best estimations of linear change trends with $95 \%$ uncertainty ranges are $0.121^{\circ} \pm 0.009^{\circ}$, $0.244^{\circ} \pm 0.021^{\circ}, 0.379^{\circ} \pm 0.045^{\circ}$, and $0.079^{\circ} \pm 0.13^{\circ} \mathrm{C}$

\begin{tabular}{|c|c|c|c|c|}
\hline & $1900-2015$ & $195 \mid-2015$ & $1979-2015$ & $1998-2015$ \\
\hline RAW & $0.107^{\circ} \pm 0.010^{\circ} *$ & $0.247^{\circ} \pm 0.021^{\circ} *$ & $0.381^{\circ} \pm 0.045^{\circ} *$ & $0.059^{\circ} \pm 0.13^{\circ}$ \\
\hline ADJ & $0.121^{\circ} \pm 0.009^{\circ} *$ & $0.244^{\circ} \pm 0.021^{\circ *}$ & $0.379^{\circ} \pm 0.044^{\circ} *$ & $0.079^{\circ} \pm 0.13^{\circ}$ \\
\hline CRUTEM4 & $0.130^{\circ} \pm 0.009^{\circ} *$ & $0.243^{\circ} \pm 0.021^{\circ} *$ & $0.348^{\circ} \pm 0.051^{\circ *}$ & $-0.150^{\circ} \pm 0.14^{\circ}$ \\
\hline GHCN & $0.114^{\circ} \pm 0.009^{\circ} *$ & $0.215^{\circ} \pm 0.021^{\circ} *$ & $0.297^{\circ} \pm 0.049^{\circ} *$ & $-0.093^{\circ} \pm 0.14^{\circ}$ \\
\hline
\end{tabular}

$*$ The trend has passed the significance test of $95 \%$. 
(not significant) decade ${ }^{-1}$ for 1900-2015, 1951-2015, 1979-2015, and 1998-2015, respectively. Thus, the average of SAT "warming” over China also shows a "slow down" during the past 18 years (1998-2015).

ACKNOWLEDGMENTS. Sincere and special thanks go to Prof. Shaowu Wang from Peking University, who had reviewed the draft of the manuscript and provided many valuable comments and suggestions. We express our deepest condolences on his passing due to illness on 11 January 2015.

This study is supported by the China Meteorological Administration Special Foundation for Climate Change (Grant CCSF201338) and the Ministry of Science and Technology of China (Grant GYHY201406016). TZ is supported by National Natural Science Foundation of China under Grant 41330423.

\section{REFERENCES}

Bradley, R. S., H. F. Diaz, P. D. Jones, and P. M. Kelly, 1987: Secular fluctuations of temperature over the Northern Hemisphere land areas and mainland China since the mid-19th century. The Climate of China and Global Climate, D. Ye et al., Eds., China Ocean Press, 76-87.

Brohan, P., J. J. Kennedy, I. Harris, S. F. B. Tett, and P. D. Jones, 2006: Uncertainty estimates in regional and global observed temperature changes: A new data set from 1850. J. Geophys. Res., 111, D12106, doi:10.1029/2005JD006548.

Cao, L., P. Zhao, Z. Yan, P. D. Jones, Y. Zhu, Y. Yu, and G. Tang, 2013: Instrumental temperature series in eastern and central China back to the 19th century. J. Geophys. Res. Atmos., 118, 8197-8207, doi:10.1002 /jgrd.50615.

Chen, L. X., and Coauthors, 2004: Characteristics of the climate change and its formation mechanism in China in last 80 years. J. Meteor. Res., 62, 634-646.

Cheng, X. Y., Y. H. Wang, G. C. Li, and Q. X. Li, 2013: Evaluation of three reanalysis precipitation datasets in China. Adv. Climate Change Res., 9, 258-265, doi:10.3969/j.issn.1673-1719.2013.04.004.

Compo, G. P., and Coauthors, 2011: The Twentieth Century Reanalysis Project. Quart. J. Roy. Meteor. Soc., 137, 1-28, doi:10.1002/qj.776.

—, P. D. Sardesmukh, J. S. Whitaker, P. Brohan, P. D. Jones, and C. McColl, 2013: Independent confirmation of global land warming without the use of station thermometers. Geophys. Res. Lett., 40, 3170-3174, doi:10.1002/grl.50425.

Ding, Y. H., and X. S. Dai, 1994: Temperature variation in China during the last 100 years. Meteorology, 20, 19-26.
Ding, Y. H., and G. Y. Ren, Eds., 2008: Introduction to China's Climate Change Sciences. China Meteorological Press, $281 \mathrm{pp}$.

Duan, A., and Z. Xiao, 2015: Does the climate warming hiatus exist over the Tibetan Plateau? Sci. Rep., 5, 13711, doi:10.1038/srep13711.

Easterbrook, D. J., 2008: Global cooling is here-Evidence for predicting global cooling for the next three decades. Center for Research on Globalization, Montreal, QC, Canada. [Available online at www .globalresearch.ca/index.php?.context=\&aid=10783.]

Easterling, D. R., and M. F. Wehner, 2009: Is the climate warming or cooling? Geophys. Res. Lett., 36, L08706, doi:10.1029/2009GL037810.

Ebisuzaki, W., 1997: A method to estimate the statistical significance of a correlation when the data are serially correlated. J. Climate, 10, 2147-2151, doi:10.1175/1520 -0442(1997)010<2147:AMTETS>2.0.CO;2.

Fyfe, J. C., N. P. Gillett, and F. W. Zwiers, 2013: Overestimated global warming over the past 20 years. Nat. Climate Change, 3, 767-769, doi:10.1038/nclimate1972.

Guemas, V., F. J. Doblas-Reyes, I. Andreu-Burillo, and M. Asif, 2013: Retrospective prediction of the global warming slowdown in the past decade. Nat. Climate Change, 3, 649-653, doi:10.1038/nclimate1863.

Gullet, D. W., L. Vincent, and P. J. F. Sajecki, 1990: Testing for homogeneity in temperature time series at Canadian climate stations. CCC Rep. 90-4, Atmospheric Environment Service, Downsview, ON, Canada, 43 pp.

Guo, Y., W. J. Dong, F. M. Ren, Z. C. Zhao, and J. B. Huang, 2013: Comparison of simulation of China's annual average air temperature by CMIP5 and CMIP3 models. Adv. Climate Change Res., 9, 181-186.

Hansen, J., R. Ruedy, M. Sato, and K. Lo, 2010: Global surface temperature change. Rev. Geophys., 48, RG4004, doi:10.1029/2010RG000345.

Hartmann, D. L., and Coauthors, 2013: Observations: Atmosphere and surface. Climate Change 2013: The Physical Science Basis, T. F. Stocker et al., Eds., Cambridge University Press, 159-254.

Hua, L. J., Z. G. Ma, and W. D. Guo, 2008: The impact of urbanization on air temperature across China. Theor. Appl. Climatol., 93, 179-194, doi:10.1007 /s00704-007-0339-8.

Jiang, D. B., and Z. P. Tian, 2013: East Asian monsoon change for the 21st century: Results of CMIP3 and CMIP5 models. Chin. Sci. Bull., 58, 1427-1435, doi:10.1007/s11434-012-5533-0.

Jin, C., and T. Zhou, 2014: Analysis of the interannual variations of the East Asian winter monsoon simulation by four CMIP5 GCMs. Chin. J. Atmos. Sci., 38, 453-468. 
Jones, P. D., P. Ya. Groisman, M. Coughlan, N. Plummer, W.-C. Wang, and T. R. Karl, 1990: Assessment of urbanization effects in time series of surface air temperature over land. Nature, 347, 169-172, doi:10.1038/347169a0.

_ , T. J. Osborn, and K. R. Briffa, 1997: Estimating sampling errors in large-scale temperature averages. J. Climate, 10, 2548-2568, doi:10.1175/1520 -0442(1997)010<2548:ESEILS>2.0.CO;2.

— , D. H. Lister, and Q. Li, 2008: Urbanization effects in large-scale temperature records, with an emphasis on China. J. Geophys. Res., 113, D16122, doi:10.1029/2008JD009916.

- - — T. J. Osborn, C. Harpham, M. Salmon, and C. P. Morice, 2012: Hemispheric and large-scale land-surface air temperature variations: An extensive revision and an update to 2010. J. Geophys. Res., 117, D05127, doi:10.1029/2011JD017139.

Karl, T. R., and C. N. Williams Jr., 1987: An approach to adjusting climatological times series for discontinuous in homogeneities. J. Climate Appl. Meteor., 26, 1744-1763, doi:10.1175/1520 -0450(1987)026<1744:AATACT>2.0.CO;2.

_ , and Coauthors, 2015: Possible artifacts of data biases in the recent global surface warming hiatus. Science, 348, 1469-1472, doi:10.1126/science.aaa5632.

Kaufmann, R. K., H. Kauppi, M. L. Mann, and J. H. Stock, 2011: Reconciling anthropogenic climate change with observed temperature 1998-2008. Proc. Natl. Acad. Sci. USA, 108, 11 790-11 793, doi:10.1073 /pnas.1102467108.

Lawrimore, J. H., M. J. Menne, B. E. Gleason, C. N. Williams, D. B. Wuertz, R. S. Vose, and J. Rennie, 2011: An overview of the Global Historical Climatology Network monthly mean temperature data set, version 3. J. Geophys. Res., 116, D19121, doi:10.1029/2011JD016187.

Lewandowsky, S., J. Risbey, and N. Oreskes, 2016: The "pause" in global warming: Turning a routine fluctuation into a problem for science. Bull. Amer. Meteor. Soc., 97, 723-733, doi:10.1175/BAMS-D-14-00106.1.

Li, Q. X., X. Liu, H. Zhang, T. C. Peterson, and D. R. Easterling, 2004a: Detecting and adjusting temporal inhomogeneity in Chinese mean surface air temperature data. Adv. Atmos. Sci., 21, 260-268, doi:10.1007 /BF02915712.

- , H. Zhang, X. Liu, and J. Huang, 2004b: Urban heat island effect on annual mean temperature during the last 50 years in China. Theor. Appl. Climatol., 79, 165-174, doi:10.1007/s00704-004-0065-4.

—,- J J. Chen, W. Li, X. Liu, and P. Jones, 2009: A mainland China homogenized historical temperature dataset of 1951-2004. Bull. Amer. Meteor. Soc., 90, 1062-1065, doi:10.1175/2009BAMS2736.1.
— W. Wong, W. Li, X. Gao, P. Jones, J. Kennedy, and D. Parker, 2010a: Assessment of the uncertainties in temperature change in China during the last century. Chin. Sci. Bull., 55, 1974-1982, doi:10.1007/s11434 -010-3209-1.

—, W. Li, P. Si, X. Gao, W. Dong, P. Jones, J. Huang, and L. Cao, 2010b: Assessment of surface air warming in northeast China, with emphasis on the impacts of urbanization. Theor. Appl. Climatol., 99, doi:10.1007/s00704-009-0155-4.

—, J. Huang, Z. Jiang, L. Zhou, P. Chu, and K. Hu, 2014: Detection of urbanization signals in extreme winter minimum temperature changes over northern China. Climatic Change, 122, 595-608, doi:10.1007 /s10584-013-1013-z.

— S. Yang, W. Xu, X. Wang, P. Jones, D. Parker, L. Zhou, and Y. Feng, 2015: China experiencing the recent warming hiatus. Geophys. Res. Lett., 42, 889-898, doi:10.1002/2014GL062773.

Li, Z., and Z. Yan, 2009: Homogenized daily mean/ maximum/minimum temperature series for China from 1960-2008. Atmos. Ocean. Sci. Lett., 2, 237-243, doi:10.1080/16742834.2009.11446802.

Met Office, 2013a: The recent pause in global warming (1): What do observations of the climate system tell us? Met Office Rep., 27 pp. [Available online at www .metoffice.gov.uk/media/pdf/q/s/Paper1_Observing _changes_in_the_climate_system.PDF.]

- 2013b: The recent pause in global warming (2): What are potential causes? Met Office Rep., 22 pp. [Available online at www.metoffice.gov.uk/media /pdf/q/0/Paper2_recent_pause_in_global_warming .PDF.]

_ 2013c: The recent pause in global warming (3): What are the implications for projections of future warming? Met Office Rep., 19 pp. [Available online at www.gci.org.uk/Documents/Paper3_Implications _for_projections.pdf.]

Morice, C. P., J. J. Kennedy, N. A. Rayner, and P. D. Jones, 2012: Quantifying uncertainties in global and regional temperature change using an ensemble of observational estimates: The HadCRUT4 data set. J. Geophys. Res., 117, D08101, doi:10.1029/2011JD017187.

Peterson, T. C., and Coauthors, 1998: Homogeneity adjustments of in situ atmospheric climate data: A review. Int. J. Climatol., 18, 1493-1517, doi:10.1002 /(SICI)1097-0088(19981115)18:13<1493::AID-JOC329 $>3.0 . \mathrm{CO} ; 2-\mathrm{T}$.

Qin, D. H., Y. H. Ding, and J. L. Su, Eds., 2005: Evolution of China's Climate and Environment. Vol. 1, Science Press, $986 \mathrm{pp}$.

Ren, G., Y. Zhou, Z. Chu, J. Zhou, A. Zhang, J. Guo, and X. Liu, 2008: Urbanization effects on observed 
surface air temperature trends in North China. J. Climate, 21, 1333-1348, doi:10.1175/2007JCLI1348.1.

Ren, Y., and G. Ren, 2011: A remote-sensing method of selecting reference stations for evaluating urbanization effect on surface air temperature trends. J. Climate, 24, 3179-3189, doi:10.1175/2010JCLI3658.1.

Song, F., Q. Hu, and W. H. Qian, 2004: Quality control of daily meteorological data in China, 1951-2000: A new dataset. Int. J. Climatol., 24, 853-870, doi:10.1002/joc.1047.

Tang, G., and G. Y. Ren, 2005: Reanalysis of surface air temperature change of the last 100 years over China. Climatic Environ. Res., 10, 791-798.

Taylor, K. E., 2001: Summarizing multiple aspects of model performance in a single diagram. J. Geophys. Res., 106, 7183-7192, doi:10.1029/2000JD900719.

_, R. J. Stouffe, and G. A. Meehl, 2012: An overview of CMIP5 and the experiment design. Bull. Amer. Meteor. Soc., 93, 485-498, doi:10.1175/BAMS-D-11-00094.1.

Tu, Q. P., 1984: Trend and cycle of China's air temperature variation in the past century. J. Nanjing Inst. Meteor., 7, 151-162.

Vose, R. S., and Coauthors, 2012: NOAA's merged landocean surface temperature analysis. Bull. Amer. Meteor. Soc., 93, 1677-1685, doi:10.1175/BAMS-D-11-00241.1.

Wang, F., Q. Ge, S. Wang, Q. Li, and P. Jones, 2015: A new estimation of urbanization's contribution to the warming trend in China. J. Climate, 28, 8923-8938, doi:10.1175/JCLI-D-14-00427.1.

Wang, J., C. Xu, M. Hu, Q. Li, Z. Yan, P. Zhao, and P. D. Jones, 2014: A new estimate of the China temperature anomaly series and uncertainty assessment in 1900-2006. J. Geophys. Res. Atmos., 119, 1-9, doi:10.1002/2013JD020542.

Wang, S., and D. Gong, 2000: Enhancement of the warming trend in China. Geophys. Res. Lett., 27, 2581-2584, doi:10.1029/1999GL010825.

_ - J. L. Ye, and D. Y. Gong, 1998: Construction of mean annual temperature series for the last one hundred years in China (in Chinese). Quart. J. Appl. Meteor. Sci., 9, 392-401.
Xu, W., Q. Li, X. L. Wang, S. Yang, L. Cao, and Y. Feng, 2013: Homogenization of Chinese daily surface air temperatures and analysis of trends in the extreme temperature indices. J. Geophys. Res. Atmos., 118, 9708-9720, doi:10.1002/jgrd.50791.

Xu, Y., and C. H. Xu, 2012: Preliminary assessment of simulations of climate changes over China by CMIP5 multi-models. Atmos. Ocean. Sci. Lett., 5, 489-494.

Yan, Z., Z. Li, Q. X. Li, and P. D. Jones, 2009: Effects of site change and urbanisation in the Beijing temperature series 1977-2006. Int. J. Climatol., 30, 1226-1234, doi:10.1002/joc.1971.

Yang, X. C., Y. L. Hou, and B. D. Chen, 2011: Observed surface warming induced by urbanization in east China. J. Geophys. Res., 116, D14113, doi:10.1029/2010JD015452.

Zhai, P., Q. Chao, and X. Zou, 2004: Progress in China's climate change study in the 20th century. J. Geogr. Sci., 14, 3-11.

Zhang, J., W. Dong, L. Wu, J. Wei, P. Chen, and D.-K. Lee, 2005: Impact of land use changes on surface warming in China. Adv. Atmos. Sci., 22, 343-348, doi:10.1007/BF02918748.

Zhang, L., Y. H. Ding, T. W. Wu, and X. G. Xin, 2013: The 21st century annual mean surface air temperature change and the $2^{\circ} \mathrm{C}$ warming threshold over the globe and China as projected by the CMIP5 models. J. Meteor. Res., 71, 1047-1065.

Zhang, X. G., and X. Q. Li, 1982: Some characteristics of temperature variation in China in the present century. J. Meteor. Res., 40, 198-208.

Zhou, L., R. E. Dickinson, Y. Tian, J. Fang, Q. Li, R. K. Kaufmann, C. J. Tucker, and R. B. Myneni, 2004: Evidence for a significant urbanization effect on climate in China. Proc. Natl. Acad. Sci. USA, 101, 9540-9544, doi:10.1073/pnas.0400357101.

Zhou, T., and R. Yu, 2006: Twentieth-century surface air temperature over China and the globe simulated by coupled climate models. J. Climate, 19, 5843-5858, doi:10.1175/JCLI3952.1. 
Hurricane Pioneer:

Memoirs of

Bob Simpson

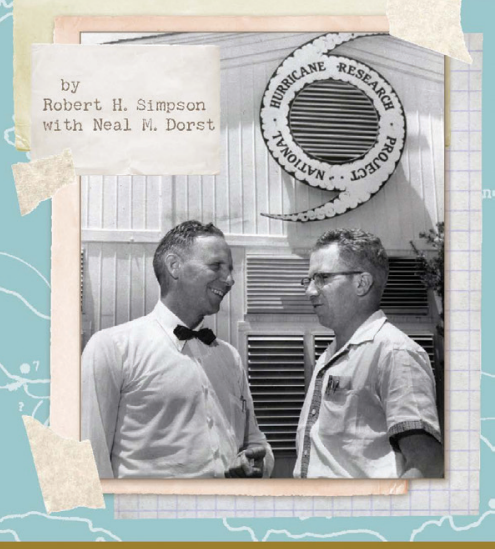

AMERICAN METEOROLOGICAL SOCIETY

Browse online at ametsoc.org/bookstore

FREE SHIPPING for AMS Members!

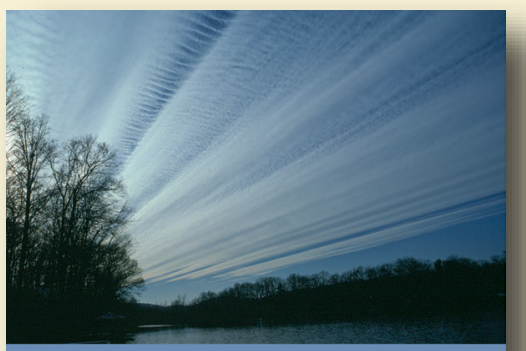

AN OBSERVER'S GUIDE to

CLOUDS AND WEATHER

A NORTHEASTERN PRIMER ON PREDICTION TOBY CARLSON, PAUL KNIGHT, AND CELIA WYCKOFF

\section{HURRICANE PIONEER}

Memoirs of Bob Simpson

Robert H. Simpson with Neal M. Dorst

In 1951, Bob Simpson rode a plane directly into the wall of a hurricane-just one of his many pioneering explorations. This autobiography of the first director of the National Hurricane Research Project and co-creator of the SaffirSimpson Hurricane Scale starts with childhood rememmbrance and ends in first-hand account of a revolutionary

(c) 2014, PAPERBACK

ISBN: 978-1-935704-75-1

LIST \$30 MEMBER \$20

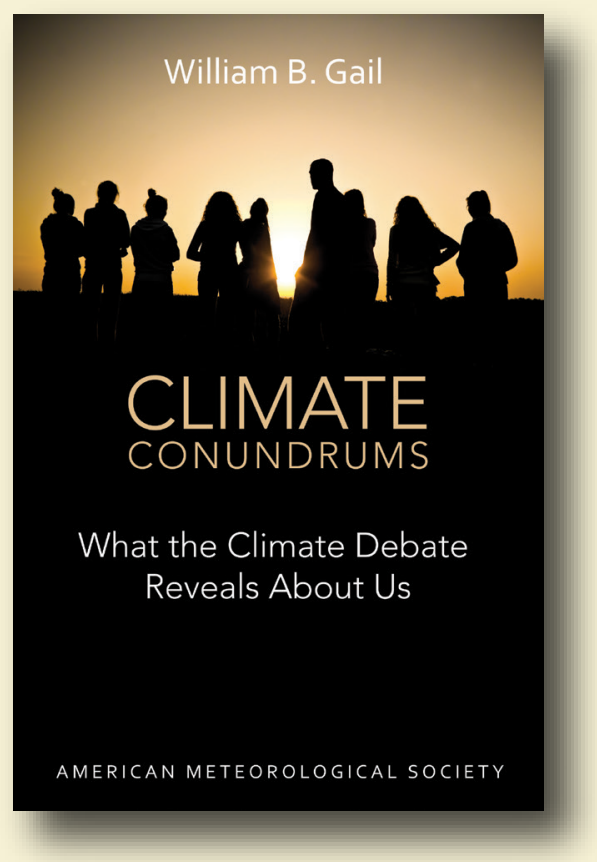

CLIMATE CONUNDRUMS What the Climate Debate Reveals About Us

William B. Gail

This is a journey through how we think, individually and collectively, derived from the climate change debate. With wit and wisdom, Gail explores several questions: Can we make nature better? Could science and religion reconcile? Insights from such issues can help us better understand who we are and help

(C) 2014, PAPERBACK

ISBN: 978-1-935704-74-4

LIST \$30 MEMBER \$20

\section{AN OBSERVER'S GUIDE TO CLOUDS AND WEATHER}

A Northeast Primer on Prediction

Toby Carlson, Paul Knight, and Celia Wyckoff

With help from Penn State experts, start at the beginning and go deep. This primer for enthusiasts and new students alike will leave you with both refined observation skills and an understanding of the complex science behind the weather: the ingredients for making reliable predictions of your own.

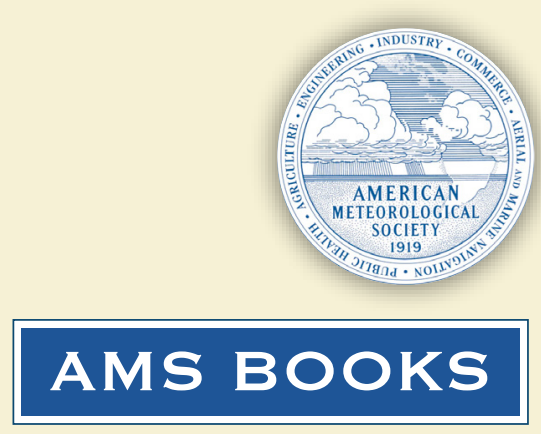

AMS Books are available to groups and booksellers, and desk copies may be obtained, through our distributor 